\title{
Timectomia estendida por cirurgia torácica videoassistida e cervicotomia no tratamento da miastenia*
}

\author{
Extended thymectomy through video assisted thoracic \\ surgery and cervicotomy in the treatment of myasthenia
}

\author{
Eduardo haruo Saito ${ }^{1}$ (te sbct), Cláudio higa ${ }^{2}$ (Te sbct), Rodolfo acatauassu Nunes ${ }^{3}$ (te sbct), \\ Gérson C. Magalhães ${ }^{4}$, Luiz Carlos Aguiar VaZ ${ }^{5}$, Vicente Faria Cervante ${ }^{6}$
}

\begin{abstract}
Introdução: A relação entre a miastenia e o timo é evidente e o tratamento atual desta condição inclui a timectomia. No entanto, uma revisão de nossa experiência com a timectomia revelou a necessidade do uso de uma técnica mais radical.
\end{abstract}

O bjetivo: Analisar retrospectivamente pacientes portadores de miastenia gravis que foram submetidos a timectomia radical por videotoracoscopia, ressaltando vantagens do método, complicações, análise histopatológica e resultados em relação ao controle da doença.

Material e método: Vinte e um pacientes miastênicos (18 do sexo feminino e três do sexo masculino, com idade variando de 17 a 51 anos) foram submetidos a timectomia por videotoracoscopia bilateral associada a cervicotomia transversa com ressecção da glândula tímica, dos tecidos peritímicos e das gorduras pericárdicas direita e esquerda. Todos os tecidos implicados foram analisados pela anatomia patológica separadamente. Houve acompanhamento por período médio de 39,2 meses.

Resultados: Não houve mortalidade operatória. O correram duas $(9,5 \%)$ lesões vasculares e um $(4,8 \%)$ paciente passou a apresentar disfonia leve permanente. Dezenove $(90,4 \%)$ pacientes estão com boa evolução, sem medicação ou com dose reduzida da mesma. A histopatologia demonstrou 10 hiperplasias do timo, seis involuções tímicas e cinco timos normais. A presença de tecido tímico ectópico foi detectada em seis $(28,6 \%)$ pacientes.

Conclusão: A timectomia radical por videotoracoscopia ofereceu bom controle da miastenia gravis. Fez-se ressecção de tecido tímico ectópico em alguns pacientes. (J Pneumol 2003;29(5):273-9)

Descritores - Tórax. Cirurgia assistida por vídeo. Miastenia gravis. Timectomia.

* Trabalho realizado na Faculdade de Ciências M édicas da U niversidade do Estado do Rio de J aneiro - UERJ/HUPE.

1. Professor Adjunto Doutor - Disciplina de Cirurgia Torácica. Título de especialista pela Sociedade Brasileira de Cirurgia Torácica.

2. Professor A ssistente - Disciplina de Cirurgia Torácica. Título de especialista pela Sociedade Brasileira de Cirurgia Torácica.

3. Professor Adjunto Doutor - Disciplina de Cirurgia Torácica. Título de especialista pela Sociedade Brasileira de Cirurgia Torácica.
Background: The relationship between myasthenia and the thymus is evident and the current treatment of this condition includes thymectomy. However, a revision of our experience with thymectomy has revealed the necessity of a more radical technique.

O bjective: To analyze, retrospectively, myasthenia gravis patients who underwent videothoracoscopic radical thymectomy, emphasizing the advantages and drawbacks of the methodology, pathological findings and results related to disease control.

Material and methods: Twenty-one myasthenic patients (18 females and 3 males, aged 17 to 51 years), underwent videothoracoscopic bilateral thymectomy associated to transverse cervicotomy for removal of the thymus gland and surrounding tissues, and right and left pericardiac fat tissues. Those tissues were separately sent to pathology analysis. The mean time of follow-up was 39.2 months.

Results: There were no intra-operative deaths. Two patients $(9.5 \%)$ suffered vascular injury, and one patient $(4.8 \%)$ presented a low level permanent dysphonia. Nineteen patients $(90.4 \%)$ are doing well, with none or low dose medications. Pathology studies showed 10 hyperplastic thymuses, 6 with involution and 5 with normal aspect. Ectopic thymic tissue was found in six patients (28.6\%).

Conclusion: Videothoracoscopic radical thymectomy offered a good control of myasthenia gravis. Additionally, ectopic thymus tissue was removed from some patients.

Key words - Thorax. Surgery, video-assisted. Myastenia gravis. Thymectomy.
4. Professor Titular - Disciplina de Neurologia.

5. Professor A djunto Doutor - Disciplina de Patologia.

6. Professor Adjunto - Disciplina de N efrologia.

Endereço para correspondência - H ospital U niversitário Pedro Ernesto, Av. 28 de Setembro, 77 - 4ํandar - Cirurgia Torácica, Vila Isabel - 20551-030 - Rio de J aneiro, RJ. Tel.: (21) 2587-6163.

Recebido para publicação em 25/9/02. Aprovado, após revisão, em 12/6/03. 


\section{INTRODUÇÃO}

A miastenia gravis (MG) é uma doença auto-imune decorrente de alterações da junção neuromuscular. É caracterizada, clinicamente, por fatigabilidade anormal prolongada dos músculos estriados, os quais pioram com a ação repetitiva ou tensão e recuperam a força com o repouso ou com o uso de inibidores da colinesterase. Sua relação com o timo é evidente e o tratamento atual da sua forma generalizada inclui a timectomia.

Revendo a experiência com a timectomia no Hospital Universitário Pedro Ernesto, foi revelada a necessidade da adoção de uma técnica mais radical, uma vez que o levantamento da evolução dos pacientes operados pela técnica transcervical demonstrou baixo benefício com relação ao controle da doença $(38,5 \%$ de pacientes reoperados e com restos tímicos). (1) 0 achado de restos tímicos após a ressecção transcervical também ocorreu com outros autores como Henze et al.(2) (27\% de reoperações com restos tímicos), Masaoka et al.(3) e Mineo et al.,(4) este último tendo realizado as reoperações por videotoracoscopia.

A cirurgia torácica videoassistida (CTVA) trouxe uma nova opção de tratamento com a possibilidade de realizar uma ressecção mais radical, sem esternotomia.

Para analisar os resultados da timectomia no controle da MG é necessário longo período de seguimento dos pacientes submetidos a esse tipo de tratamento, pois alguns melhoram quase imediatamente após a cirurgia e outros podem levar até 10 anos para demonstrar algum benefício. 0 objetivo maior de nosso trabalho foi analisar retrospectivamente os pacientes operados por esse método, ressaltando suas vantagens, complicações, análise histopatológica e eficiência no controle da MG.

\section{Método}

A nalisamos neste trabalho 21 pacientes portadores de MG operados pela técnica da timectomia estendida no Hospital U niversitário Pedro Ernesto/ UERJ acompanhados no ambulatório de Cirurgia Torácica e de Neurologia de maio de 1996 a maio de 2002. Definimos como timectomia estendida a ressecção não somente da glândula tímica, mas também das gorduras pericárdicas direita e esquerda, associadas a uma exploração cervical com o objetivo de ressecar tecido tímico ectópico (tecido tímico encontrado fora da glândula tímica). Esses pacientes eram portadores de MG sem timoma, três $(14,3 \%)$ eram do sexo masculino e os demais do sexo feminino $(85,7 \%)$; a idade dos pacientes variou de 17 a 51 anos, com média de 29,7 anos. Dezenove pacientes apresentavam a MG generalizada com acometimento da musculatura com inervação bulbar, caracterizando a classe IIB de $0 \operatorname{sserman}^{(5)} \mathrm{e}$
Siglas e abreviaturas utilizadas neste trabalho

CTI - Centro de terapia intensiva

CTVA - Cirurgia torácica videoassistida

MG - Miastenia gravis

SUS - Sistema Ú nico de Saúde

$V E F_{1}$ - Volume expiratório forçado no primeiro segundo

dois eram da classe IIA. Utilizamos uma graduação em números, proposta por Calhoun et al.(6), para avaliar os sinais e sintomas desses pacientes: $0=$ assintomático; 1 = sinais e sintomas oculares; 2 = fraqueza generalizada leve; 3 = fraqueza generalizada moderada e/ ou disfunção bulbar; 4 = fraqueza generalizada intensa e/ ou disfunção respiratória. A média pré-operatória foi de 2,95.

A os pacientes foi informada, detalhadamente, a nova técnica e todos consentiram em realizar a cirurgia por esse método com a possibilidade de conversão para esternotomia, caso não se conseguisse realizar a ressecção ou houvesse alguma complicação. 0 projeto inicial dessa nova abordagem foi aprovado pela Comissão Científica (Parecer 063/1996).

Estabelecido o diagnóstico de MG, os pacientes com a forma generalizada foram encaminhados, pelo Serviço de Neurologia, para serem submetidos à cirurgia. Em todos, foi realizada avaliação com exames pré-operatórios. Os pacientes foram operados com a doença controlada usando-se uma associação de anticolinesterásico (brometo de piridostigmina) e corticóide (prednisona), em doses segundo as manifestações clínicas.

Como preparo pré-operatório, os pacientes com a classe IIB foram submetidos a plasmaferese com duas a três sessões com intervalo de 24 horas entre elas, sendo a última realizada na véspera da operação. 0 período de preparo pré-operatório foi em média de cinco dias.

Todos os pacientes foram intubados com tubo endotraqueal de duplo-lume.

A posição do paciente para a realização da cirurgia foi o decúbito dorsal horizontal com os braços abertos. 0 hemitórax direito foi abordado inicialmente e o esquerdo, posteriormente. Foi utilizado um arco de metal para apoiar o elevador de esterno localizado no nível da fúrcula esternal, elevado a $40 \mathrm{~cm}$ de altura da mesma (Figura 1 ).

Duas equipes, uma posicionada na cabeceira e a outra do lado direito da mesa cirúrgica, iniciavam o procedimento. A dissecção cervical era realizada com uma incisão transversa anterior de cerca de 6 a $8 \mathrm{~cm}, 2 \mathrm{~cm}$ acima da fúrcula esternal. A videotoracoscopia, inicialmente à direita e posteriormente à esquerda, era realizada com três trocartes de $10 \mathrm{~mm}$, um localizado entre a linha hemiclavicular e a linha axilar anterior, no $2 \circ$ espaço intercostal e os outros dois, nos 3 o e 5 o espaços intercostais, linha axilar anterior, com a retirada não somente do timo, 


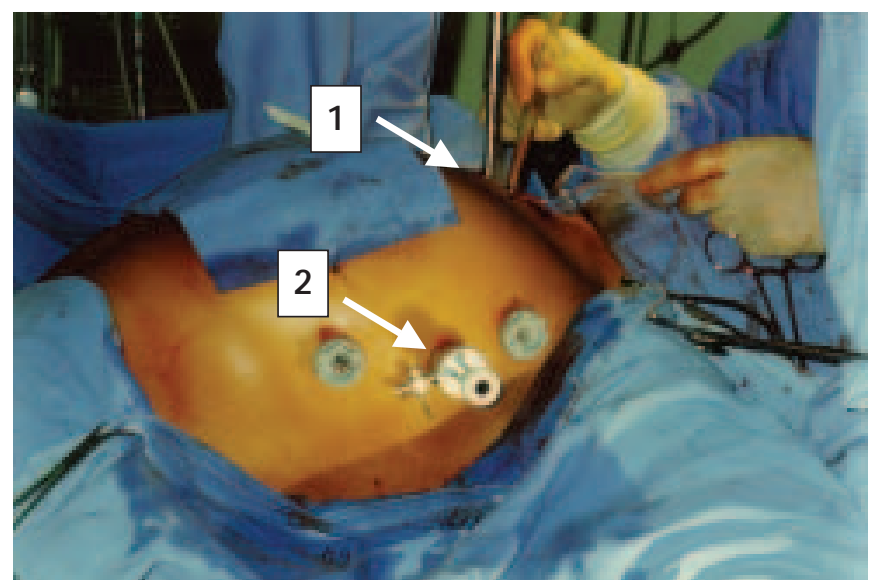

Figura 1 - Localização do elevador de esterno ao nível do manúbrio (seta 1) e dos trocartes posicionados na região lateral do hemitórax esquerdo (seta 2). Paciente em decúbito dorsal horizontal com os braços abertos.

mas também da gordura pericárdica e de todo o tecido peritímico, bilateralmente, como descrito na metodização desta técnica. ${ }^{(7)}$ Todos os tecidos ressecados foram retirados pela incisão cervical. Durante a operação o nervo frênico era visualizado e cuidadosamente preservado.

\section{Resultados}

Não houve mortalidade operatória. 0 tempo operatório médio foi de 210 minutos. Dois pacientes necessitaram suporte ventilatório no pós-operatório e permaneceram por período prolongado no centro de terapia intensiva (CTI) (60 dias e 15 dias), um deles com pneumonia. Todos os outros casos foram extubados ainda na sala de operação, permanecendo cerca de 24 horas no CTI ou unidade intermediária. Os drenos foram retirados, em média, com dois dias de pós-operatório. Houve média de permanência pós-operatória hospitalar de 7,6 dias (média de 12,6 dias de internação).

Houve fácil controle do quadro doloroso, com analgésicos (dipirona ou paracetamol) e antiinflamatórios não hormonais, que foram mantidos regularmente nos primeiros dois dias do período pós-operatório. Esse esquema de analgesia foi feito em todos os pacientes, associado a bloqueios com bupivacaína a 0,5\% dos nervos intercostais correspondentes aos orifícios dos trocartes.

Seis pacientes apresentaram disfonia, logo nos primeiros dias de pós-operatório, a qual progressivamente meIhorou em cinco $(23,8 \%)$ e permaneceu em um $(4,8 \%)$ paciente. Neste doente a laringoscopia demonstrou paralisia de corda vocal esquerda com melhora parcial da disfonia após sessões de fonoaudiologia. Nos que apresentaram disfonia transitória a laringoscopia não foi realizada.

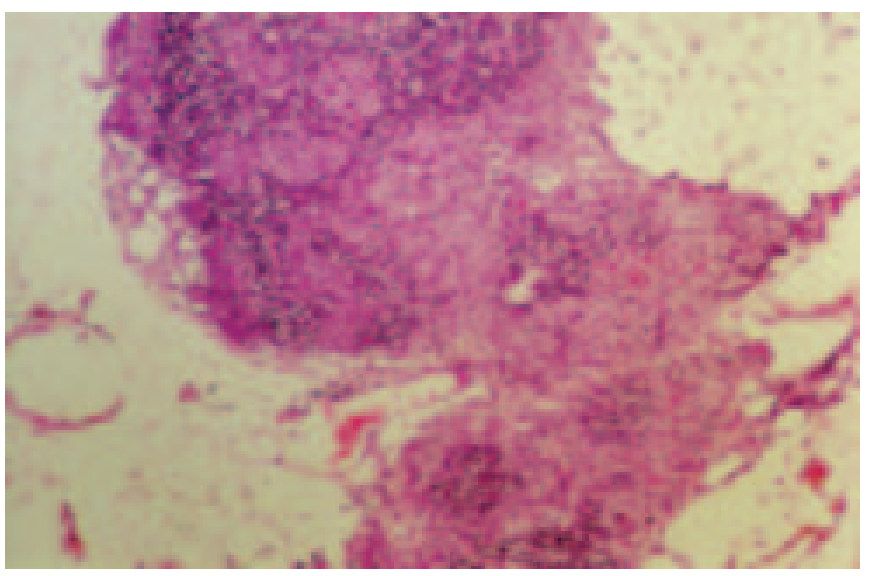

Figura 2 - Em meio a gordura pericárdica, presença de tecido tímico $(40 x)$

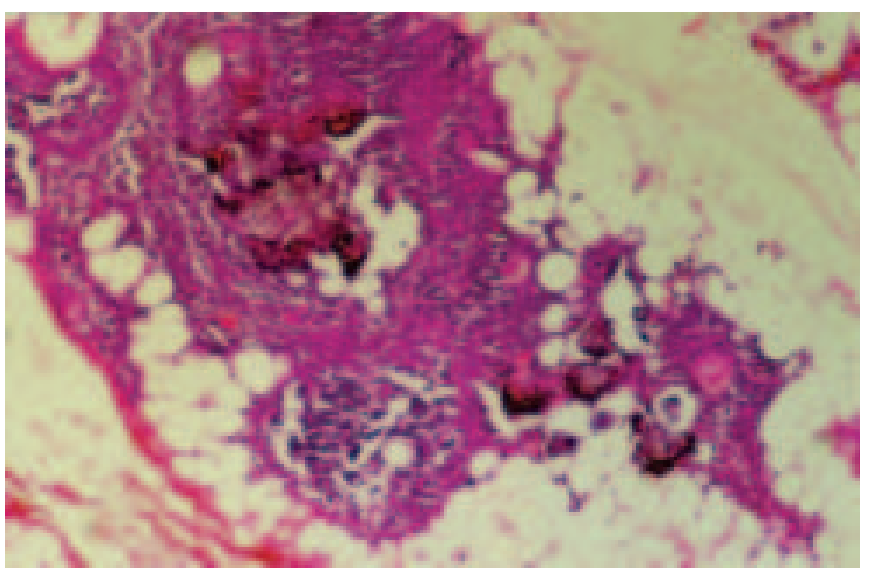

Figura 3 - Detalhe da figura anterior. Tecido tímico com corpúsculo de Hassal, alguns calcificados (100x).

Houve duas $(9,5 \%)$ lesões vasculares, ocorridas durante a dissecção cervical. U ma lesão foi de artéria inominada que necessitou de esternotomia para o reparo, sendo este um paciente que já tinha sido submetido a uma timectomia supra-esternal, com presença ainda de tecido tímico e sem melhora clínica. A outra lesão foi de veia torácica interna esquerda, a qual foi reparada pela cervicotomia.

Todos os pacientes retornaram à medicação utilizada para o controle da MG, logo no primeiro dia de pós-operatório.

O período de acompanhamento desses pacientes variou de 12 a 65 meses, com média de 39,2 meses. Dos 21 pacientes, $19(90,4 \%)$ apresentaram boa evolução (controle clínico fácil): três estão sem uso de qualquer medicação para controle da MG, 15 estão com uso de dose reduzida da medicação e um está com uso da mesma dose da medicação. Todos estes estão assintomáticos 
ou com poucos sintomas. Dois $(10,5 \%)$ pacientes não tiveram melhora após a timectomia, com difícil controle clínico, e um apresentou crise miastênica desencadeada por infecção urinária e faleceu no quarto mês de pósoperatório. Trata-se de uma paciente que havia sido submetida a reoperação pós-timectomia transcervical com presença de fragmentos de tecido tímico.

As peças cirúrgicas foram encaminhadas à patologia, separadas: timo, gordura pericárdica direita, gordura pericárdica esquerda e outros tecidos peritímicos quando presentes. Rigorosamente, o timo era separado das gorduras pericárdicas com a cápsula intacta, de forma que não foram observados casos de fragmentação desta glândula com as gorduras e tecidos peritímicos. Os resultados histopatológicos foram: $10(47,6 \%)$ hiperplasias tímicas, seis $(28,6 \%)$ involuções tímicas e cinco $(23,8 \%)$ timos normais.

Um achado de grande interesse na análise histopatológica foi a presença de tecido timíco ectópico (não sendo uma fragmentação da glândula) em seis $(28,6 \%)$ pacientes. Cinco apresentavam-no na gordura pericárdica esquerda e um, nas gorduras pericárdicas direita e esquerda e na região cervical (Figuras 2 e 3 ).

\section{DISCUSSÃO}

Na MG, a timectomia é geralmente indicada nos pacientes com a forma generalizada e que necessitam de aumentos progressivos das medicações de controle (riscos dos efeitos colaterais) ou que apresentam má resposta a estas medicações, com a presença de crises miastênicas. ${ }^{(8)}$

A timectomia transcervical, que compreende a ressecção do timo por uma incisão cervical, é uma técnica utilizada por alguns cirurgiões que relatam vantagens como: mobilização precoce no pós-operatório, presença de pouca dor e bom controle da miastenia gravis (em até $90 \%$ dos casos), com resultados comparáveis aos da timectomia por esternotomia e poucas complicações. ${ }^{(6,9)}$ Alguns cirurgiões apontam como a maior desvantagem dessa técnica a retirada incompleta da glândula, com manutenção do quadro miastênico em até 20 a $30 \%$ dos pacientes, e necessidade de reoperação (a falha mais comum foi a "fragmentação" da glândula, às vezes com lobos inteiros mantidos intactos). ${ }^{(3,10)}$

A timectomia pode também ser realizada por esternotomia total ou parcial, com ou sem abertura das pleuras, associada ou não à exploração cervical. A boa resposta a essa técnica pode chegar a $85 \%$ nos pacientes submetidos a esternotomia parcial.(11,12) Das várias técnicas de timectomias, a que realmente proporciona ressecção completa é a cirurgia proposta por J aretzki (timectomia "máxima" por cervicotomia e esternotomia mediana total), com $96 \%$ de bons resultados. ${ }^{(13)}$ Dessa forma, baseandose na experiência desse cirurgião, foi proposta uma técnica alternativa objetivando a ressecção completa sem a necessidade da esternotomia: a timectomia estendida por cirurgia torácica videoassistida bilateral associada a uma cervicotomia transversa.

A pós a realização da cirurgia nos quatro primeiros casos deste estudo, foi encontrado, na revisão da literatura, relato de uma técnica semelhante, com apenas algumas pequenas diferenças na colocação dos trocartes. Isso vem reforçar não a intenção de originalidade, mas a possibilidade de realização da timectomia estendida na miastenia gravis utilizando a CTVA. ${ }^{(14)}$

Em conjunto com a timectomia estendida, a cervicotomia se fez necessária para explorar todos os possíveis locais de tecido tímico ectópico, como enfatizado por J aretzki. ${ }^{(13)}$ Sem a cervicotomia seria difícil, de nosso ponto de vista, a exploração completa de tecido tímico ectópico somente pela videotoracoscopia. O utra importância deste acesso é a facilidade da dissecção dos pólos superiores do timo e a secção dos ligamentos tireotímicos direito e esquerdo, junto à tireóide, certificando-se de que não foi deixado nenhum fragmento do timo nessa região. Entretanto, alguns autores realizam a timectomia sem a cervicotomia e relatam conseguir boa liberação dos pólos superiores até o pescoço por dissecção romba. ${ }^{(15,16)}$

0 acesso por videotoracoscopia para a ressecção somente da glândula tímica pode ser tanto pela direita (mais freqüente $\left.{ }^{(15,16)}\right)$, quanto pela esquerda. ${ }^{(17)}$ Entretanto, neste caso, faz-se a ressecção do timo e perde-se a possibilidade de ressecar as gorduras mediastinal e pericárdica bilateralmente, locais em potencial de tecido tímico ectópico o qual, de acordo com estudo de J aretzki, ${ }^{13)}$ ocorre de fato em $52 \%$ dos pacientes. A retirada da gordura é fácil de ser realizada, pois, uma vez no plano correto, a simples dissecção romba faz o descolamento da gordura da superfície pericárdica, com pouco sangramento, pela inexistência de vasos calibrosos na região.

A ressecção do timo com tripla visão, uma transcervical e as outras videotoracoscópicas direita e esquerda, é importante para a retirada completa e, caso haja a secção acidental da glândula, o fragmento pode ser ressecado sem problemas quando se retira o bloco da gordura pericárdica. Isso ocorreu em três pacientes e as peças foram cuidadosamente separadas em tecido tímico e gordura. Em todos os casos, o timo, a gordura pericárdica direita e a gordura pericárdica esquerda foram enviados, separadamente, para a anatomia patológica. A constatação da presença de tecido tímico na gordura pericárdica em seis pacientes de nossa casuística reforça os achados de J aretzki. (13)

Q uando se compara o tempo operatório e o tempo de internação, verifica-se que as cirurgias menos invasivas 
como a timectomia transcervical são mais rápidas de ser realizadas (média de $104 \mathrm{~min}$ ) e com menor período de internação (média de um dia). ${ }^{(6)}$ As técnicas mais estendidas levam mais tempo, como a timectomia por CTVA esquerda (média de 148min e média de internação de 5,2 dias) e a cervicoesternotomia total (média de $163 \mathrm{~min}$ e média de internação de 5,8 dias). ${ }^{(18-20)} \mathrm{Em}$ nossa casuística, o tempo operatório foi, nos primeiros pacientes, de 360 min e, nos últimos, de $180 \mathrm{~min}$, com média de $210 \mathrm{~min}$ e tempo médio de internação de 12,6 dias. 0 período maior de internação foi devido à realização de três sessões de plasmaferese pré-operatória, com intervalo de 24 horas em 19 pacientes, e porque, destes, dois permaneceram por maior período no CTI.

As principais razões de maior tempo operatório, principalmente nos primeiros pacientes, foram a dificuldade de localizar bem os trocartes com freqüente colisão de pinças e a ocorrência de hipoxemia com a ventilação seletiva, havendo necessidade de ventilar o pulmão colapsado, sendo obrigatória, por várias vezes, a interrupção da operação. A instalação de pressão positiva contínua nas vias aéreas, mantendo fluxo contínuo de oxigênio no pulmão colapsado, foi utilizada para corrigir esse quadro. Entretanto, algumas vezes a pressão positiva contínua tinha que ser interrompida, pois o pulmão insuflado dificultava a cirurgia.

A plasmaferese foi empregada no preparo de 19 dos nossos pacientes que apresentavam comprometimento dos músculos com inervação bulbar (deglutição e respiração). Destes, 17 foram extubados na sala de operação. A plasmaferese utilizada no pré-operatório de pacientes miastênicos contribuiu para a diminuição significativa no período de ventilação mecânica no pós-operatório e menor permanência em unidades de recuperação, conforme estudos de D'Empaire et al. (21) e Yusta et al. (22)

A nalisando o pós-operatório dos pacientes, não foi encontrada, em nenhum deles, queixa álgica conseqüente à compressão dos nervos intercostais provocada pela manipulação dos trocartes durante a cirurgia. Em nossos pacientes foi feito de rotina o bloqueio dos nervos intercostais com bupivacaína a 0,5\%; essa complicação, que pode ser comum após videotoracoscopia, ${ }^{(23,24)}$ não ocorreu. Nenhum paciente se queixou de dor pela presença de drenagem bilateral (utilizaram-se drenos de 28 a 30 $F R$ ). Os drenos foram retirados entre o segundo e o terceiro dia de pós-operatório. O controle fácil da dor no período pós-operatório foi também observado nos pacientes operados por Novelino et al. (14)

A s complicações encontradas por J aretzki et al. ${ }^{(25)} \mathrm{em}$ 95 timectomias por cervicoesternotomia foram: dois pacientes com infecção (empiema bilateral e osteomielite de esterno), dois com síndrome pós-pericardiotomia, um com deiscência de esterno, um com quilotórax bilateral e um com embolia pulmonar. As complicações relacionadas ao acesso cirúrgico (osteomielite e deiscência do esterno) não foram encontradas na presente casuística pela não abertura do esterno.

Com relação às complicações hemorrágicas $(9,5 \%)$, os acidentes ocorreram pela dissecção cervical e não pela videotoracoscopia. 0 maior acidente ocorreu em um caso de reoperação (falha da ressecção transcervical) com reparo por esternotomia. 0 estudo de Papatestas et al. ${ }^{(32)}$ mostra que nos primeiros 15 pacientes de sua casuística submetidos a timectomia transcervical, três (20\%) apresentaram lesões vasculares com necessidade de esternotomia.

A disfonia (cinco transitórias e uma persistente) ocorreu por causa da cervicotomia, na busca da máxima ressecção. Há relatos dessa complicação nas cirurgias transcervicais ${ }^{(32)}$ e por esternotomia. ${ }^{(33)}$ Bulkley et al., ${ }^{(20)}$ realizando timectomia "máxima" por cervicoesternotomia, relataram três pacientes com disfonia persistente e um com transitória. O controle clínico fácil observado em $90,4 \%$ dos casos, após média de 39,2 meses de acompanhamento, demonstra resultados animadores do método. Mantegazza et al. (26) observaram $70 \%$ de remissão completa e remissão farmacológica em 101 pacientes submetidos a timectomia estendida por videotoracoscopia bilateral associada a cervicotomia transversa. Mack et al. (27) já observaram $87,9 \%$ de boa evolução em 33 pacientes submetidos a timectomia por CTVA direita e Mineo et al.,(18) $96 \%$ de boa evolução em 31 pacientes operados por CTVA esquerda.

Rückert et al. ${ }^{(28)}$ realizaram um trabalho prospectivo e randomizado comparando a função pulmonar (capacidade vital, capacidade vital funcional, volume expiratório forçado no 1 o segundo - $\mathrm{VEF}_{1}$ e peak flow) de 20 pacientes, 10 submetidos a timetomia por CTVA esquerda e 10 a timectomia por esternotomia total. O bservaram, no pósoperatório, redução de $35 \%$ da função pulmonar nos pacientes submetidos a timectomia por CTVA e $65 \%$ nos pacientes operados por esternotomia. A recuperação da função pulmonar foi completa no terceiro dia de pós-operatório no grupo operado por CTVA; isso ocorreu em apenas $55 \%$ dos pacientes operados por esternotomia. A menor redução da função pulmonar e a recuperação mais rápida da mesma foram observadas nos pacientes operados por CTVA. A demais, nesses pacientes, a menor intensidade da dor constituiu um dos fatores de maior relevância.

Dos dois pacientes que não tiveram boa resposta com a timectomia radical, um apresentava tecido tímico hiperplasiado em meio da gordura pericárdica esquerda. 0 outro é uma paciente, a qual constituiu a única reoperação por vídeo da presente casuística, por piora do quadro miastênico após timectomia transcervical realizada cinco 
anos antes, com presença de tecido tímico residual. A importância clínica desse achado foi muito bem discutida por Ashour et al.,(29) que observaram pior resposta pósoperatória nos pacientes que apresentavam tecidos tímicos ectópicos. Scelci et al. ${ }^{\left({ }^{(3)}\right)}$ relataram o achado de 14,8\% de casos com timo ectópico na região pré-traqueal e $33,3 \%$ no mediastino anterior, utilizando a técnica da timectomia estendida por videotoracoscopia bilateral associada a cervicotomia transversa. Mineo et al.(18) encontraram tecido tímico ectópico em 32,3\% dos pacientes submetidos a timectomia por CTVA esquerda.

A importância de realizar uma ressecção mais ampla do timo e dos tecidos adjacentes ainda é muito discutida. J aretzki(31) fez uma comparação dos resultados de várias séries de timectomias, desde as realizadas pela técnica transcervical até as técnicas mais estendidas. Essa análise demonstrou que as ressecções mais estendidas melhoram a freqüência de remissão. 0 mesmo autor relata dois problemas na comparação das diversas técnicas de timectomias: 1) a média de acompanhamento das séries da timectomia transcervical foi de 8,4 anos, enquanto que a dos procedimentos com ressecções mais estendidas foi de 3,3 anos, e sabe-se que a freqüência de remissão no pós-operatório aumenta com o tempo; 2) nas séries em que se realizaram as timectomias transcervicais, analisadas pelo autor, foram operados pacientes portadores de miastenia gravis da forma mais branda quando comparados com as séries em que se realizaram as timectomias mais estendidas.

Mineo et al. ${ }^{(18)}$ relatam $96 \%$ de bons resultados em pacientes submetidos a timectomias por CTVA esquerda, que apresentavam média pré-operatória de classificação de
2,16. A média pré-operatória na presente casuística foi de 2,95, traduzindo uma maior parte de pacientes miastênicos com acometimento da musculatura de inervação bulbar (IIB de Osserman). Calhoun et al. ${ }^{(6)}$ apresentaram excelentes resultados com a técnica transcervical, com média pré-operatória de classificação de 2,70, porém estes resultados não foram repetidos pelo nosso Serviço. Outro ponto importante a ser considerado é o tempo de acompanhamento: o presente resultado, já satisfatório, poderá melhorar ainda mais quando houver maior período de acompanhamento.

A tualmente, a CTVA é um procedimento amplamente realizado em diversas situações e várias instituições já contam com a aparelhagem, que é a mesma da cirurgia videolaparoscópica. A timectomia por CTVA utiliza os mesmos instrumentais da videolaparoscopia, acrescidos apenas de tubo seletivo endotraqueal para ventilação monopulmonar (preço, em média, de cem dólares). Assim, é possível a realização desse procedimento em instituições do Sistema Ú nico de Saúde (sus), principalmente pela não utilização de grampeadores, cujos custos não são repassados pelo sus e aumentam muito os valores envolvidos em uma CTVA.

Com o presente estudo, concluímos que a timectomia estendida por videotoracoscopia bilateral associada a cervicotomia ofereceu aos pacientes controle adequado da miastenia gravis e possibilitou a ressecção, em alguns pacientes, de tecido tímico ectópico. Existe, todavia, a necessidade de um número maior de procedimentos e um acompanhamento a mais longo prazo para obter uma melhor análise desta técnica alternativa de timectomia.

\section{REFERÊNCIAS}

1. Higa C, Nunes RA, Saito EH, Guimarães AN. Timectomia "maxima" para miastenia grave. Pulmão (RJ) 1997;6:34-40.

2. Henze T, Nenner M, Michaelis HC. Determination of erythrocyte-bound acetylcholinesterase activity for monitoring pyridostigmine therapy in myasthenia gravis. J Neurol 1991;238:225-9.

3. Masaoka A, Monden Y, Seike Y, Tanioka T, Kagotani K. Reoperation after transcervical thymectomy for myasthenia gravis. Neurology 1982 ; 32:83-5.

4. Mineo TC, Pompeo E, Ambrogi V, Bernardi G, lani C, Sabato AF. $V$ ideo-assisted completion thymectomy in refractory myasthenia gravis. J Thorac Cardiovasc Surg 1998;115:252-4.

5. Osserman KE, Genkins G. Studies in myasthenia gravis: review of a twenty year experience in over 1200 patients. Mt Sinai J Med 1971; 38:497-537

6. Calhoun RF, Ritter J H, Guthrie TJ , Pestronk A, M eyers BF, Patterson $\mathrm{GA}$, et al. Results of transcervical thymectomy for myasthenia gravis in 100 consecutive patients. Ann Surg 1999;230:555-61.

7. Saito EH, Higa C, Nunes RA, Ribeiro-N etto A, Guimarães AN, Hadad $\mathrm{R}$, et al. Metodização da técnica da timectomia radical por vídeotoracoscopia bilateral associada a cervicotomia transversa na miastenia gravis. Pulmão (RJ) 1998;7:130-40.

8. Lanska DJ . Indicatons for thymectomy in myasthenia gravis. Neurology $1990 ; 40: 1828-9$.

9. Shrager J B, Deeb ME, Mick R, Brinster CJ , Chielders HE, Marshall $M B$, et al. Transcervical thymectomy for myasthenia gravis achieves results comparable to thymectomy by sternotomy. Ann Thorac Surg 2002;74:320-6

10. Henze A, Biberfeld P, Christensson B, Matell G, Pirskanen R. Failing transcervical thymectomy in myasthenia gravis. Scand J Thorac Cardiovasc Surg 1984;18:235-8.

11. Cohn HE, Solit RW, Schartz NJ , Schlezinger N. Surgical treatment in myasthenia gravis. J Thorac Cardiovasc Surg 1974;68:876-81.

12. Pêgo-Fernandes PM, Milanez de Campos J R, J atene FB, Marchiori $P$, Suso FV, O liveira SA. Thymectomy by partial sternotomy for the treatment of myasthenia gravis. Ann Thorac Surg 2002;74:204-8.

13. J aretzki III A, Bethea M, Wolff M, Olarte MR, Lovelace RE, Penn AS, et al. A racional approach to total thymectomy in the treatment of myasthenia gravis. Ann Thorac Surg 1977;24:120-30.

14. Novelino L, Longoni M, Spinelli L, Andretta M, Cozzi M, Faillace G, et al. "Extended" thymectomy, without sternotomy, performed by cervicotomy and thoracoscopic technique in the treatment of myasthenia gravis. Int Surg 1994;79:378-81. 
15. A cuff TE. Thoracoscopy for mediastinal masses and thymectomy. In: Brown WT, editor. Atlas of video-assisted thoracic surgery. Philadelphia: W.B. Saunders, 1994;245-9.

16. Yim APC, Kay RLC, Ho J KS. Video-assisted thoracoscopic thymectomy for myasthenia gravis. Chest 1995;108:1440-3.

17. Kaiser LR. Video-assisted thoracic surgery. Current state of the art. Ann Surg 1994;220:720-34.

18. Mineo TC, Pompeo E, Lerut TE, Bernardi G, Coosemans W, Nofroni I. Thoracoscopic thymectomy in autoimmune myasthenia: results of left-sided approach. Ann Thorac Surg 2000;69:1537-41.

19. Lennquist S, Andaker Lars, Lindvall B, Smeds S. Combined cervicothoracic approach in thymectomy for myasthenia gravis. Acta Chir Scand 1990:156:53-61.

20. Bulkley GB, Bass KN, Stephenson GR, Diener-West M, George S, Reilly $P A$, et al. Extended cervicomediastinal thymectomy in the integrated management of myasthenia gravis. Ann Surg 1997;226:324-35.

21. D'Empaire G, Hoaglin DC, Perlo PV, Pontoppidan H. Effect of prethymectomy plasma exchange on postoperative respiratory function in myasthenia gravis. J Thorac Cardiovasc Surg 1985;89:592-6.

22. Yusta $A$, J iménez MD, Liaño $H$. Plasmaferésis en el tratamiento de la miastenia gravis. Rev Clin Esp 1986;179:65-8.

23. Mulder DS. Pain management principles and anesthesia techniques for thoracoscopy. Ann Thorac Surg 1993;56:630-2.

24. Richardson J, Sabanathan S. Pain management in video assisted thoracic surgery: evaluation of localized partial rib resection. A new technique. J Cardiovasc Surg 1995;36:505-9.
25. Jaretzki A, Penn AS, Younger DS, Wolf M, O larte MR, Lovelace RE, et al. "Maximal" thymectomy for myasthenia gravis. Results. J Thorac Cardiovasc Surg 1988;95:747-57.

26. Mantegazza R, Confaloniere P, Antozzi C, Novelino L, Ferrò MT, Porta $M$, et al. Video-assisted thoracoscopic extended thymectomy (VATET) in myasthenia gravis. Two-year follow-up in 101 patients and comparison with the transsternal approach. Ann N Y Acad Sci 1998;841: 749-52.

27. Mack MJ , Landreneau RJ , Y im AP, H azelrigg SR, Scruggs GR. Results of video-assisted thymectomy in patients with myasthenia gravis. J Thorac Cardiovasc Surg 1996;112:1352-60.

28. Rückert J C, Walter M, Müller J M. Pulmonary function after thoracoscopic thymectomy versus median sternotomy for myasthenia gravis. Ann Thorac Surg 2000;70:1656-61.

29. A shour M. Prevalence of ectopic thymic tissue in myasthenia gravis and its clinical significance. J Thorac Cardiovasc Surg 1995;109:632-5.

30. Scelsi R, Ferrò MT, Scelsi L, Novelino L, Mantegazza R, Cornelio F, et al. Detection and morphology of thymic remnants after video-assisted thoracoscopic extended thymectomy (VATET) in patients with myasthenia gravis. Int Surg 1996;81:14-7.

31. J aretzki A. O utcome after transcervical thymectomy. Ann Thorac Surg 1999;67:592-3.

32. Papatestas AE, GenkinsG, Kornfeld P, Eisenkraft J B, Fagerstran RP, Pozner J, et al. Effects of thymectomy in myasthenia gravis. Ann Surg 1987;206:79-88.

33. Späth G, Brinkmann A, Huth C, Wietholter H. Complications and efficacy of transsternal thymectomy in myasthenia gravis. Thorac Cardiovasc Surg 1987;35:283-9. 